\title{
Re-cycling a city - examining the growth of cycling in Dublin
}

\author{
Brian Caulfield \\ Department of Civil, Structural and Environmental Engineering, Trinity College \\ Dublin, Dublin 2, Ireland
}

\begin{abstract}
In the past few decades much research has been conducted on the increasing numbers of commuters taking up cycling to work. This modal shift has been encouraged by pro-cycling policies to increase the attractiveness of cycling and the construction of new cycling infrastructure. In Dublin, several policies have been applied such as a bike rental scheme, bicycle-purchasing schemes, reducing speed limits and the construction of segregated cycle lanes to promote cycling. This paper seeks to examine what, if any, impact these policies have had on cycling rates in Dublin. This paper compares census data from 2006 and 2011 to determine how cycling rates have changed and if the demographics of cyclists have changed in the city. The results presented in the paper show that cycling rates have increased in Dublin and that a greater percentage of females, those in higher age and socio-economic groups are cycling to work on a regular basis. The analysis presented in this paper identifies groups of individuals that have recently shifted to cycling to work, by identifying who these people are, policymakers can tailor strategies to target these groups to encourage others in these groups to take up cycling.
\end{abstract}

\section{Background and Introduction}

Dublin is the capital city of Ireland and has a population of 1.2 million (CSO, 2012). The topography of the city is relatively flat which makes it an ideal candidate city for cycling. Dublin has a mild climate with on average $61 \mathrm{~mm}$ of rain per month. This compares with $64 \mathrm{~mm}$ in Amsterdam, $44 \mathrm{~mm}$ in Copenhagen and $78 \mathrm{~mm}$ in Freiburg, all cities with a traditional reputation of being the most cycle friendly cities in the world (World.Climate.com, 2012). Given the climate and topography of Dublin it is an ideal candidate for improving growth in cycling rates.

Since 2008, there has been a concerted effort in Dublin to improve the image of cycling in the city and to increase the modal share of cycling. These policies are discussed in the next section. Internationally, several authors have written about increasing the modal share of cycling. A growing literature in the area points to several factors that are responsible for the growth of the mode share of cycling. Pucher and Buehler (2006) in a comparison of cycling rates between the United States and Canada cite increased car ownership costs, safer cycling environments and investments infrastructure as factors responsible for higher rates of cycling in Canada compared to the United States. Pucher et al (2011a) conducted a similar study comparing Sydney to Melbourne. In Melbourne, the authors found that cycling rates were twice those experienced in Sydney. The authors attribute this to climate, topography and infrastructure for the difference in cycling rates. However the study also cites public advocacy of cycling in Melbourne as one of the reasons for the growth of cycling in the city.

Pucher et al (2011b) examine the increases in cycling in North America over the past two decades. The authors find that while cycling rates to work have grown, 
the most substantial increases were shown to have happened in cities that have actively promoted the mode and have invested in cycling infrastructure. Numerous studies have shown that cyclists have a better perception of cycling than non-cyclists (Caulfield et al, 2012; Lawson et al, 2012; Gatersleben and Appleton, 2007).

Other studies have examined the propensity to cycle using large datasets. Vandenbulcke et al (2011) used data from the 2001 census in Belgium to determine what factors impacted upon cycling rates. This study found that several factors including town size, demographic characteristics impacted upon the propensity to cycle. Wardman et al (2007) used data from the National Travel Survey in the UK to determine what policies could increase the potential to cycle to work. The results of this study found that improved on-route facilities and financial incentives would increase the numbers who cycle on a daily basis. McMillan (2007) examines the potential of children to use non-motorised modes of transport to travel to school using census data from the USA. The author used the data to determine what factors influence the propensity to use these non-motorised modes of transport and found that urban form played a large part in the decision to use one of these modes of transport.

The literature shows several examples of positive interventions that can be conducted to improve cycling up take in urban areas. A consensus is being reached in the literature that shows that a two-pronged approach of segregated infrastructure and behavioral change is required to encourage individuals to cycle to work on a regular basis. The results presented in this paper show how the bundle of policies implemented in Dublin have been used to improve cycling. While the data used in the study cannot single out the impact of any one single intervention, the findings do show how cycling in the city has increased and how the demographics of those that cycle to work has changed. The paper contributes to the field of research by showing how Dublin, a city with a traditionally low cycling base has changed to a city with increasing numbers of cyclists.

The research objectives of this paper are to examine how cycling patterns have changed in the two census periods examined in the paper and to ascertain how the demographics of cyclists have changed in Dublin. To determine what changes have happened in cycling in the city, a multinomial logistic regression model was estimated to show the relationships between a series of variables and increases in cycling rates. By identifying those groups that have switched to cycling recently it is aimed to identify those that are 'near market' or in other words, those most likely to switch to cycling. This will then allow policymakers to tailor solutions, campaigns and other interventions at these groups to encourage more people to take up cycling.

\section{Policy Interventions to Improve Cycling in Dublin}

This section of the paper describes the different policy interventions in Dublin to encourage cycling under five headings. When encouraging cycling, like any other mode of transport, it requires the use of push and pull factors making cycling seem more attractive and other modes less attractive (Rietveld and Daniel, 2004). The policies described in this section of the paper describe mainly the push factors used in Dublin to achieve a modal shift to cycling.

\subsection{Financial Incentives}

Financial incentives have often been used as a policy measure encourage effective sustainable modal shift. In Ireland one such policy was the introduction of tax-free loans to purchase bicycles. Caulfield and Leahy (2011) examined how individuals 
that purchased bicycles under the tax-free loan system in Ireland had used their bicycles. The findings of the study showed that $48 \%$ individuals that hadn't owned a bicycle in over seven years were now cycling on a weekly basis and the main reasons for this take up in cycling was attributed to health benefits and the flexibility of the mode.

\subsection{Infrastructure provision and traffic calming}

One of the barriers to cycling is a perceived poor safety record. Cycling in Dublin is generally perceived as unsafe by both experienced cyclist and non-cyclists, but the increased provision cycle lanes may change this perception (Lawson et al, 2012). Caulfield et al (2012) also found that the provision of segregated cycle lanes in Dublin can change the perception of safety and further increase the attractiveness of cycling in the city. To improve the safety of cyclists and the attractiveness of the mode, over $120 \mathrm{~km}$ of cycle lanes have been constructed in Dublin since 1990, $25 \mathrm{~km}$ of which are off-road cycle tracks (Dublin City Cycling, 2012). In tandem with the introduction of this new cycling infrastructure, Dublin City Council has introduced traffic calming measures by introducing $30 \mathrm{~km}$ speed limits in the city centre. The city council has also constructed a freight tunnel in the city called the Dublin Port Tunnel. The tunnel, opened in 2006 , extends for $5.6 \mathrm{~km}$ and connects the Port of Dublin with the outer motorway. Prior to the tunnel opening in 2006 heavy goods vehicles (HGV's) would have had to travel through the city centre. Since opening, any HGV with five or more axels has been banned from the city centre. The construction of the tunnel has removed largest vehicles from the streets of Dublin city making it a more attractive place to walk and cycle.

\subsection{Promotion}

One of the key elements encouraging modal shift in Dublin has been though the promotion of cycling. One of the largest promotions is an annual national event called Bike Week. Bike Week has been running since 2009. During the week several events happen in Dublin such as several planned family cycles, removing traffic from streets, bicycle repair clinics, talks and several events at schools to encourage children to cycle (Bike Week, 2013). To encourage children to walk and cycle to school an initiative called "Safer routes to school" was launched in 2000 (Dublin Transportation Office, 2005). In 1996, just 1.3\% of all school children (aged between 5 and 12) cycled to school (CSO, 2011). To increase this number, the safer routes to school initiative worked with schools, teachers and students to demonstrate the benefits of walking and cycling to school. In 2006, $1.8 \%$ of school children in this group cycled to school and this improved to $2.4 \%$ in 2011 (CSO, 2011). These figures are modest, but show a movement in a more sustainable direction.

\subsection{Share Bicycle Scheme}

Dublin, like many other international cities, has introduced a shared bike scheme called Dublin Bikes. In 2011, the year the data in this paper was collected, there were 44 Dublin Bikes stations in the city, housing 550 bicycles. The scheme has been very successful with over three million trips recorded in the first three years (Dublin Bikes, 2012). Research into the usage of the scheme has shown the trips made using the scheme are commuting trips and that prior to the introduction of Dublin Bikes the majority these trips were made by walking or public transport (O'Neill and Caulfield, 2012). Due to the success of the initial stages of the scheme it is planned to increase 
the number of stations from 44 to 102 and increase the number of bikes to over 1,500 (Dublin Bikes, 2013).

\subsection{Policy and political support}

One of the keys to the success of any transport initiative is policy and political support. Cycling in Dublin and in Ireland has and continues to have both political and policy support. In 2009, the Irish Department of Transport set out ambitious targets for increasing cycling from a base of less than $2 \%$ in 2009 to $10 \%$ of all trips by 2020 (Department of Transport, 2009a). It has still yet to be seen if these targets can be realised. In the same year the Department of Transport launched the first national cycle policy framework document, which pledged government support for cycling and promised the appropriate funding to deliver the strategy. Policymakers have also sought to support the design of cycling lanes, junctions and other facilitates by publishing the first design standards document for cycling in Ireland (National Transport Authority, 2011). This document is seen as a large step forward in the design of coherent and continuous cycle lanes in Ireland.

\section{Methodology}

\subsection{Data}

The data used in this paper is taken from the 2011 and 2006 census of Ireland (CSO, 2011, 2006). The data examined in this paper represent individual's regular trips to work; by the mode of transport they state that they use the most often. While this data is not ideal, especially when examining cycling, due to the seasonal variations in cycling, it is the only data source available in Ireland that can compare changes in modal share over time. The data set has 1.8 million individuals work trips in 2006 and 1.7 million individuals work trips in 2011, in Ireland. The data provided from the Irish census is for all individuals resident in Ireland and the data is provided at an individual level (which is anonymised). The data analysed in this paper relates to all those individuals that are in employment at the time of the census. This makes the data used in this research more robust than that used in other countries, as it is not a sample of the population. It should be noted that the results presented in this paper relate to the commute to work. Typically these trips account for a quarter of all trips (CSO, 2009).

\subsection{Model formulation}

In order to determine the factors that have impacted upon the growth in cycling in Dublin a multinomial logit regression model was estimated. While it would have been ideal to analyse the data using a spatial multivariate model, the dataset provided did not allow for this, as it was not possible to match records from each dataset. Therefore the matching took place using the electoral districts as shown in Figures 3 to 5 below. The dataset has been segmented into three groups: areas that have seen an increase in cycling, those that have seen a decrease and those that have experienced no change. A multinomial logistic regression analysis was used to examine the relationships between cycling rates and several demographic factors. The regression takes the following format: 
$\operatorname{logit}(\mathrm{p})=\log \frac{p}{1 p}=a+I+T+e$

where $p$ is the probability that the event occurs (in this case that a person lives in an area with no change or an increase in cycling), $\beta I$ is the set individual specific characteristics (such as age and gender), $\delta T$ is the set of transport characterises (such as departure time and travel time) and $e$ is a random error term. The variables used in the model are defined in Table 1. When interpreting the values in Table 1 for departure time, travel time in the census respondents are asked to provide information on their usual departure time and travel time, so these values may vary.

$<<$ TABLE $1>>$

\section{Results}

This section of the paper presents the results of the analysis undertaken on the census data. To put the results from Dublin in the past five years into context, Table 2 presents the Census results from 1986 to 2011 for the three largest cities in Ireland. Cork, the Republic of Ireland's second largest city (population 198,000) and Galway, the third largest city (population 93,000) are examined. The results show that Dublin has the greatest share of workers cycling to work in Ireland. The results show that in Dublin while the 2011 modal share of cyclists has dropped compared to the results in 1996, the absolute number of cyclists has increased. Lawson et al (2013) presents a detailed analysis of non-motorized trips in Irish cities and gives context as to how Dublin compares to other Irish cities.

$<<$ TABLE $2>>$

Figure 1 presents the results from the COPENHAGENIZE index from 2013 (COPENHAGENIZE, 2013). The index created by looking at thirteen different criteria such as bicycle facilities and infrastructure, cycle sharing schemes, modal increases since 2006, perceptions of safety and advocacy. These criteria are produced in an index with a maximum score of 100. The results presented in Figure 1 show Dublin has a score of 60 and is ranked $9^{\text {th }}$, this is an increase from the score of 58 that it received in 2011 (COPENHAGENIZE, 2013). These results show how the city is improving its international reputation as a cycling friendly city and the authors of the index state: "Dublin is the Great Bike Hope among Emerging Bicycle Cities" (COPENHAGENIZE, 2013).

\section{$<<$ FIGURE $1>>$}

The first set of results presented in this section examines the rates on increasing cycle traffic in Dublin. Dublin City Council conducts an annual cordon count of traffic entering the city in the month of November. Figure 2 presents the growth in percentage share of cycling from 2006 to 2011. These percentages represent the total share cycling as a percentage of total modal share. The results show that since 2006 there has been a steady increase in the number of cyclist entering the city. When interpreting these results one should be aware that these counts are conducted in November, and as such the cycling numbers at this time of year would be lower than in other months due to the poor weather at this time of year in Dublin. 
The results presented in the following figures refer to the percentage modal share of cycling for trips to work. Figures 3 and 4 present the percentages of modal share of cycling in Dublin in 2006 and 2011 respectively. The figures show that between the two time periods that there has been an increase in those cycling to work. Figure 5 shows the percentage change in modal share of cycling in Dublin. The change in cycling is represented by overall changes in each electoral district in the city. The findings show that substantial changes have occurred in the city in the period 20062011. The results show that in the city centre cycling has increased its modal share in some areas by as much as $10 \%$. The results also show the areas of greatest decline in cycling have occurred in the south west of the city. Figure 5 also shows that the growth in cycling has mainly occurred in the specific areas close to the city centre and many areas have seen little or no growth in cycling and some areas have seen a substantial decline in cycling.

$<<$ FIG $3>>$

$<<$ FIG $4>>$

$<<$ FIG 5>>

Table 3 below shows the differences between modal shares from 2011 to 2006 in Dublin, Cork and Galway. The findings show that while Dublin has experienced a $1 \%$ increase in cycling it has also experienced a $1 \%$ fall in walking to work. The results also show that over $50 \%$ of those traveling to work do so by car and alone. The results from Cork and Galway show that from 2006 to 2011 the percentage modal share of those cycling did not change. Interestingly, in all three cities the research examined the numbers walking to work decreased and the percentage of those driving alone to work in Cork and Galway increased. When comparing Dublin to the two other cities, it can be seen that Dublin has experienced larger growth in cycling numbers. Whilst Dublin has not managed to reduce the percentage of those driving alone to work, the numbers of those driving alone to work in Cork and Galway increased.

While this increase in cycling is nowhere near as close as the successes in cities like Seville, it shows how Dublin is a city in transition and how policies have been effective in increasing modal share. It should also be noted that the results from Table 3 show that perhaps the modal shift to cycling has been at the cost of other sustainable modes of transport such as walking or taking public transport as the numbers of those driving to work alone remain static.

$<<$ TABLE $3>>$

Table 4 presents the results for the changes in a number of demographic and trip characteristics of those cycling between 2006 and 2011 for Dublin, Cork and Galway. The first set of results look at the changes in the gender profile of those cycling in each of the cities. The results show that in each of the cities a greater share of females cycle to work on a daily basis. The age of cyclist displays a trend across all three cities with a decline in those in the 15-24 age group cycling and an increase in those 
cycling in the 35-44 and 45-54 age groups. The third set of results presented in Table 4 relate to departure time. The results from those in Dublin show that a higher percentage of cyclists were departing later to work. A similar trend was found in Cork and Galway, however to a lesser extent compared to the Dublin results. The results for socio-economic groups show that in each of the cities examined, more individuals in higher socio-economic groups such as employers and managers and higher and lower professionals. The results for changes in the shares between the socio-economic groups show similar trends in increases and decreases in similar groups. The final set of results presented in Table 3 relate to changes in travel time for cyclists in each of the cities examined. The results for travel time show that on average in each of the three cities that travel times by bicycle increased.

$<<$ TABLE $4>>$

Table 5 presents the results from the multinomial logit models. The model compares areas with no changes in cycling and increases in cycling to areas that experienced a decrease in cycling. The first set of results examined in Table 5 show the variables that represent gender. The coefficients estimated for female were shown to be negative and significant. While there has been an increase in cycling amongst females, one would still expect a negative coefficient for the female variable indicating that males are still more likely to cycle compared to females. The results for age show that individuals living in areas with increases in cycling are more likely to be aged 35-54. This result mirrors with the results presented in Table 4, this finding suggests that while those in the 35-44 and 45-54 age groups are more likely to cycle, more work needs to be done in these areas with growth in cycling to encourage those in the younger age groups to cycle. The model results for car ownership show that those living in areas with no change in cycling were more likely to own more than one car, whereas those living in areas with an increase in cycling were shown to be most likely to have only one car per household. This result suggests that the areas with the highest growth in cycling are areas with fewer cars available.

The results for departure time show that those living in areas with an increase in cycling were found to have later departure times than those living in areas with an increase in cycling. This finding demonstrates that those individuals living in areas with increases in cycling numbers will have more time to spend at home before departing to work. The results for travel time show that in the areas with no change in cycling numbers that the travel time coefficients are all negative. This indicates that individuals' living in areas is more likely to have journey times greater than 31 minutes. The final set of coefficients presented in Table 5 represent the socioeconomic grouping of individuals. The results show that those living in areas with an increase in cycling are marginally more likely to be individuals in the higher socioeconomic groups such as employers and managers and higher and lower professionals. This trend corresponds to the other results presented in the paper and shows the growing trend in the results showing that those in the higher socio-economic groups have begun cycling to work in between the two time periods. The results presented in the model attempt to demonstrate the characteristics of the groups in the different areas examined and to ascertain which individuals have taken up cycling and to identify those that are likely to start cycling. 


\section{Discussion and Conclusions}

One of the key findings of this research is that while some of the policies for encouraging cycling seem to be effective, perhaps more targeted policies should be adopted to reach those on the verge of switching to cycling as their main mode of transport. A similar study conducted in the UK to determine the success of a cycling policy launched in 1996 to double the amount of cycling Gaterslben and Appleton (2007), concluded that more targeted approaches are needed to encourage modal shift to cycling and that there was no one size fits all policy. This is what is seen in this paper.

The results presented in this paper show a city in transition from a low cycling base to a city that embraces cycling as a sustainable and viable alternative to mechanised modes of transport. Dublin is a comparable to many other global cities and the lessons learned in Dublin could be applied in many other cities. While the analysis presented in this paper can't pinpoint any single measure as being responsible for the modal shift towards cycling, it does show the effectiveness of the package of measures used in Dublin.

The findings of the paper show that the growth in cycling has been rather focused upon the city centre area and many areas show no increase or a decline in cycling. This increase in the centre of Dublin perhaps is a result of the majority of investment in cycle infrastructure and the lowering of speed limits has focused in this area. It should be also noted that the bike share scheme is only operational in this city centre area.

One of the key findings of the paper is the identification of the changes in demographics in cyclists in the city. A key target group to target to take up cycling are females and those in with higher incomes that have car availability. The results in this paper show that there has been a 5\% increase in females cycling to work and a substantial increase in the numbers in the higher professions cycling to work on a regular basis.

As discussed in the paper, Dublin has introduced several policies to promote cycling over the past five years. The findings in this paper point to the success of the envelope of measures used in Dublin have achieved some modal shift towards cycling. To some extent the research the research presented does underestimate the levels of cycling happening in the city, as it doesn't look at non-work trips.

Dublin, unlike other European cities has a lower cycling base and the rates of non-mechanised mode share were comparable with North American cities. However, Dublin has made substantial strides to become a cycling friendly city and to have cycling as a viable alternative to mechanised modes of transport. Lessons can be learned from the study presented in this paper for other cities both in Europe and North America on how take up and the attractiveness of cycling can be changed with a mix of new infrastructure provision and promotion of cycling.

\section{Acknowledgements}

The author would like to thank the Central Statistics Office of Ireland for kindly supplying the data used in this research. The author would also like to thank the reviewers for their helpful suggestions to improve this paper. 


\section{References}

Bike Week. Accessed on line: http://www.bikeweek.ie/ $29^{\text {th }}$ November 2013

Caulfield, B., Leahy, J., Learning to cycle again: examining the benefits of providing tax-free loans to purchase new bicycles, Research in Transportation Business \& Management, 2, 2011, pp $42-47$.

Caulfield, B., Brick, E., McCarthy, T.O. Determining bicycle infrastructure preferences - A case study of Dublin. Transportation Research Part D: Transport and the Environment, 17, 2012, 413-417.

Central Statistics Office. Census of Ireland 2006. CSO, Dublin, Ireland, 2006

Central Statistics Office. National Travel Survey, CSO, Dublin, Ireland, 2009

Central Statistics Office. Census of Ireland 2011. CSO, Dublin, Ireland, 2011

COPENHAGENIZE. Accessed on line 11/6/13:

http://www.copenhagenize.eu/index/about.html

Department of Transport, 2009a. Smarter Travel: A New Transport Policy for Ireland 2009-2020, DoT, Dublin.

Department of Transport 2009b. Ireland's First National Cycle Policy Framework, DoT, Dublin.

Dublin Bikes. Accessed on line 19/10/12: http://www.dublinbikes.ie/

Dublin Bikes. Accessed online: 29/11/2013:

http://www.dublinbikes.ie/Magazine/News/dublinbikes-New-Pricing-Structure

Dublin City Council. Report on Dublin City Councils Canal Cordon Counts 2012. Dublin City Council, 2013

Dublin City Cycling. Accessed on line 19/10/12: http://www.dublincitycycling.ie/cycling-facilities/cycle-lanes-and-facilities

Bike Week. Accessed on line 29/11/2013 http://www.bikeweek.ie/

Dublin Transportation office. Safer routes to school: Next steps, 2005, Dublin

Gatersleben, B., Appleton, K. M. Contemplating cycling to work: Attitudes and perceptions in different stages of change. Transportation Research Part A, 41, 2007, $302-312$.

Lawson, A., Pakrashi, V., Ghosh, B., Szeto, W.Y. Perception of safety of cyclists in Dublin City. Accident Analysis and Prevention, Vol 50, 2013, 499-511. 
Lawson, A., McMorrow, K., Ghosh, B. Analysis of the non-motorized commuter journeys in major Irish cities. Transport Policy, Vol 27, 2013, 179-188.

McMillan, T. The relative influence of urban form on a child's travel mode to school. Transportation Research Part A, 41, 2007, 69-79.

National Transport Authority. National Cycle Manual. 2011. Dublin

O'Neil, P. Caulfield, B., Examining user behaviour on a shared bike scheme: the case of Dublin Bikes, The 13th International Conference on Travel Behaviour Research, Toronto, 2012.

Pucher, J., Buehler, R. Why Canadians cycle more than Americans: A comparative analysis of bicycling trends and policies. Transport Policy 13 (2006) 265-279.

Pucher, J., Garrard, J., Greaves, S. Cycling down under: a comparative analysis of bicycling trends and policies in Sydney and Melbourne. Journal of Transport Geography 19 (2011a) 332-345.

Pucher, J., Buehler, R., Seiner, M. Bicycling renaissance in North America? An update and re-appraisal of cycling trends and policies. Transportation Research Part A 45 (2011b) 451-475.

Rietveld, P., Daniel, V. Determinants of bicycle use: do municipal policies matter? Transportation Research Part A, 38, 2004, 531-550.

Vandenbulcke, G., Dujardin, C., Thomas, I., de Geu, B., Degraeuwe, B., Meeusen, R., Int Panis, L. Cycle commuting in Belgium: Spatial determinants and 're-cycling' strategies. Transportation Research Part A, 45, 2011, 118-137.

Wardman, M., Tight, M., Page, M. Factors influencing the propensity to cycle to work. Transportation Research Part A, 41, 2007, 339-350.

World Climate.com. Accessed on line 7/11/12: http://www.worldclimate.com 
Table 1

Click here to download high resolution image

Table 1 Definition of variables

\begin{tabular}{|c|c|}
\hline Variable & \\
\hline \multicolumn{2}{|l|}{ Gender } \\
\hline Female & $=1$ if gender: Female \\
\hline Male & Reference category = Gender: Male \\
\hline \multicolumn{2}{|r|}{ 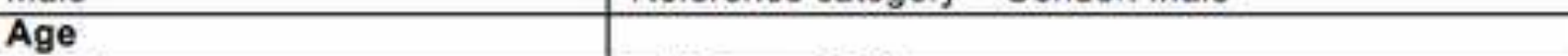 } \\
\hline $15-24$ & $=1$ if age: $15-24$ \\
\hline $25-34$ & $=1$ if age: $25-34$ \\
\hline $35-44$ & $=1$ if age: $35-44$ \\
\hline $45-54$ & $=1$ if age: $45-54$ \\
\hline $55-64$ & $=1$ if age: $55-64$ \\
\hline $65+$ & Reference category = Age: $65+$ \\
\hline \multicolumn{2}{|l|}{ Car Ownership } \\
\hline One & = 1 if car ownership: One \\
\hline Two & $=1$ if car ownership: Two \\
\hline Three & = 1 if car ownership: Three \\
\hline Four or more & $=1$ if car ownership: Four or more \\
\hline None & Reference category = Car ownership: None \\
\hline \multicolumn{2}{|l|}{ Departure Time } \\
\hline Not stated & $=1$ if departure time: Not stated \\
\hline Before 06:30 & $=1$ if departure time: Before 06:30 \\
\hline $06: 31-07: 00$ & $=1$ if departure time: 06:31-07:00 \\
\hline $07: 01-07: 30$ & $=1$ if departure time: $07: 01-07: 30$ \\
\hline $07: 31-08: 00$ & $=1$ if departure time: 07:31-08:00 \\
\hline $08: 01-08: 30$ & $=1$ if departure time: 08:01-08:30 \\
\hline $08: 31-09: 00$ & $=1$ if departure time: $08: 31-09: 00$ \\
\hline $09: 01-09: 30$ & $=1$ if departure time: 09:01-09:30 \\
\hline After 09:30 & Reference category = Departure time: After 09:30 \\
\hline \multicolumn{2}{|l|}{ Travel Time } \\
\hline Less than 5 mins & $=1$ if travel time: Less than 5 mins \\
\hline $6-10$ mins & $=1$ if travel time: $6-10$ mins \\
\hline $11-15$ mins & $=1$ if travel time: $11-15$ mins \\
\hline $16-20$ mins & $=1$ if travel time: $16-20$ mins \\
\hline $21-30 \mathrm{mins}$ & $=1$ if travel time: $21-30$ mins \\
\hline 31 mins or more & Reference category = Travel time: 31 mins or more \\
\hline \multicolumn{2}{|l|}{ Socio Economic Group (SEG) } \\
\hline Employers and managers & = 1 if SEG: Employers and managers \\
\hline Higher professional & $=1$ if SEG: Higher professional \\
\hline Lower professional & = 1 if SEG: Lower professional \\
\hline Non-manual & $=1$ if SEG: Non-manual \\
\hline Manual skilled & = 1 if SEG: Manual skilled \\
\hline Semi-skilled & $=1$ if SEG: Semi-skilled \\
\hline Unskilled & $=1$ if SEG: Unskilled \\
\hline Own account workers & $=1$ if SEG: Own account workers \\
\hline Farmers & In 1 if SEG: Farmers \\
\hline Agricultural workers & In 1 if SEG: Agricultural workers \\
\hline $\begin{array}{l}\text { All others gainfully occupied and } \\
\text { unknown }\end{array}$ & $\begin{array}{l}\text { Reference category = SEG: All others gainfully occupied } \\
\text { and unknown }\end{array}$ \\
\hline
\end{tabular}




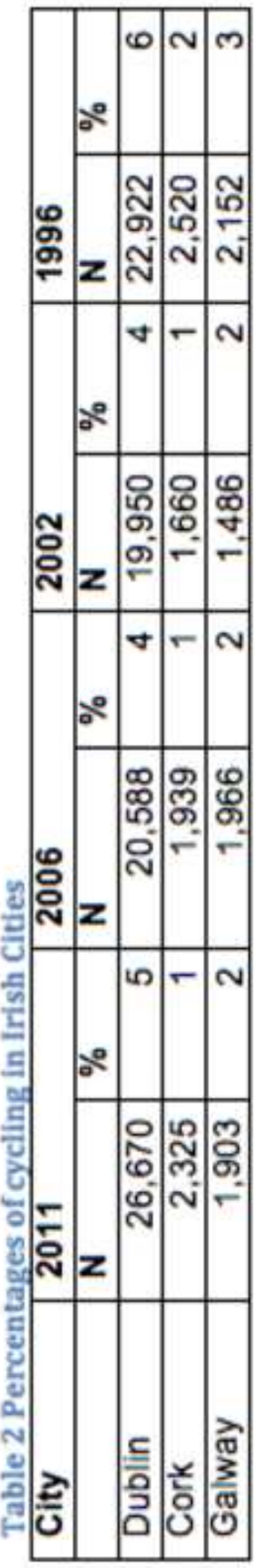

$\sim \stackrel{0}{\circ}$

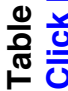


Table 3

Click here to download high resolution image

Table 3 Comparison of modal share 2006-2011 in Irish Cities

\begin{tabular}{|c|c|c|c|c|c|}
\hline Dublin & \multicolumn{2}{|r|}{2011} & \multicolumn{2}{|r|}{2006} & \multirow[t]{2}{*}{$\%$ Difference } \\
\hline Mode of transport & $\mathbf{N}$ & $\%$ & $\mathbf{N}$ & $\%$ & \\
\hline Walk & 67,680 & 13 & 70,044 & 14 & -1 \\
\hline Cycle & 26,670 & 5 & 20,588 & 4 & +1 \\
\hline Bus & 65.593 & 13 & 76,785 & 15 & -2 \\
\hline Rail & 39,717 & 8 & 39.510 & 8 & - \\
\hline Motorcycle & 4,790 & 1 & 6,607 & 1 & - \\
\hline Car & 260,751 & 51 & 260,630 & 51 & - \\
\hline Car-Passenger & 16,226 & 3 & 19,969 & 4 & -1 \\
\hline Lorry or Van & 17,040 & 3 & 19,232 & 4 & -1 \\
\hline Other Means & 1,281 & 0 & 1,027 & 0 & - \\
\hline Work from Home & 12,012 & 2 & 8,213 & 2 & - \\
\hline Total & 511,760 & 100 & 514,392 & 100 & \\
\hline Cork & & 2011 & & 2006 & $\%$ Difference \\
\hline Mode of transport & $\mathbf{N}$ & $\%$ & $\mathbf{N}$ & $\%$ & \\
\hline Walk & 19,410 & 10 & 22,183 & 11 & -1 \\
\hline Cycle & 2,325 & 1 & 1,939 & 1 & - \\
\hline Bus & 5,935 & 3 & 7,558 & 4 & -1 \\
\hline Rail & 934 & 0 & 800 & 0 & - \\
\hline Motorcycle & 813 & 0 & 1,194 & 1 & -1 \\
\hline Cat & 132,680 & 67 & 128,228 & 65 & +2 \\
\hline Car-Passenger & 8,872 & 4 & 12,820 & 6 & -2 \\
\hline Lorry or Van & 14,097 & 7 & 15,539 & 8 & -1 \\
\hline Other Means & 1,780 & 1 & 774 & 0 & +1 \\
\hline Work from Home & 10,926 & 6 & 7,487 & 4 & +2 \\
\hline Total & 197,772 & 100 & 198,522 & 100 & \\
\hline Galway & & 2011 & & 2006 & $\%$ Difference \\
\hline Mode of transport & $\bar{N}$ & $\%$ & $\mathbf{N}$ & $\%$ & \\
\hline Walk & 8,291 & 9 & 10,373 & 11 & -2 \\
\hline Cycle & 1,903 & 2 & 1,966 & 2 & - \\
\hline Bus & 2,628 & 3 & 3,216 & 3 & - \\
\hline Rail & 274 & 0 & 194 & 0 & - \\
\hline Motorcycle & 238 & 0 & 369 & 0 & - \\
\hline Car & 62,558 & 67 & 59,330 & 63 & +4 \\
\hline Car-Passenger & 3,985 & 4 & 6,527 & 7 & -3 \\
\hline Lorry or Van & 7,153 & 8 & 8,520 & 9 & -1 \\
\hline Other Means & 906 & 1 & 416 & 0 & +1 \\
\hline Work from Home & 5,444 & 6 & 3.357 & 4 & +2 \\
\hline Total & 93,380 & 100 & 94,268 & 100 & \\
\hline
\end{tabular}


Table 4

Click here to download high resolution image

Table 4 Changing demographics of cyclists in Ireland

\begin{tabular}{|c|c|c|c|c|c|c|c|c|c|}
\hline & \multicolumn{3}{|c|}{ Dublin } & \multicolumn{3}{|l|}{ Cork } & \multicolumn{3}{|c|}{ Gaiway } \\
\hline & 2011 & 2006 & $\begin{array}{l}\% \\
\text { change }\end{array}$ & 2011 & 2006 & $\begin{array}{l}\% \\
\text { change }\end{array}$ & 2011 & 2006 & $\begin{array}{l}\% \\
\text { change }\end{array}$ \\
\hline \multicolumn{10}{|l|}{ Gender } \\
\hline Male & $28 \%$ & $23 \%$ & $-5 \%$ & $76 \%$ & $79 \%$ & $-3 \%$ & $68 \%$ & $73 \%$ & $-5 \%$ \\
\hline Female & $72 \%$ & $77 \%$ & $+5 \%$ & $24 \%$ & $21 \%$ & $+3 \%$ & $32 \%$ & $27 \%$ & $+5 \%$ \\
\hline \multicolumn{10}{|l|}{ Age Group } \\
\hline $15 \cdot 24$ & $6 \%$ & $13 \%$ & $-7 \%$ & $7 \%$ & $15 \%$ & $-8 \%$ & $7 \%$ & $21 \%$ & $-14 \%$ \\
\hline $25-34$ & $39 \%$ & $39 \%$ & - & $36 \%$ & $37 \%$ & $-1 \%$ & $39 \%$ & $40 \%$ & $-1 \%$ \\
\hline $35-44$ & $29 \%$ & $23 \%$ & $+6 \%$ & $28 \%$ & $21 \%$ & $+7 \%$ & $25 \%$ & $16 \%$ & $+9 \%$ \\
\hline $45-54$ & $18 \%$ & $16 \%$ & $+2 \%$ & $20 \%$ & $16 \%$ & $+4 \%$ & $17 \%$ & $12 \%$ & $+5 \%$ \\
\hline 55.64 & $8 \%$ & $7 \%$ & $+1 \%$ & $9 \%$ & $9 \%$ & - & $10 \%$ & $8 \%$ & $+2 \%$ \\
\hline $65+$ & $1 \%$ & $1 \%$ & $=$ & $1 \%$ & $1 \%$ & - & $2 \%$ & $2 \%$ & $\cdot$ \\
\hline & & & & & & & & & \\
\hline \multicolumn{10}{|l|}{$\begin{array}{l}\text { Departure } \\
\text { time }\end{array}$} \\
\hline Not stated & $1 \%$ & $7 \%$ & $-6 \%$ & $0 \%$ & $1 \%$ & $-1 \%$ & $2 \%$ & $2 \%$ & - \\
\hline Before 6:30 & $7 \%$ & $8 \%$ & $-1 \%$ & $6 \%$ & $6 \%$ & $=$ & $6 \%$ & $7 \%$ & $-1 \%$ \\
\hline $6: 30-7: 00$ & $8 \%$ & $11 \%$ & $-3 \%$ & $9 \%$ & $10 \%$ & $-1 \%$ & $7 \%$ & $7 \%$ & - \\
\hline $7: 01-7: 30$ & $10 \%$ & $16 \%$ & $-6 \%$ & $12 \%$ & $12 \%$ & $+1 \%$ & $8 \%$ & $10 \%$ & $-2 \%$ \\
\hline $7: 31-8: 00$ & $16 \%$ & $20 \%$ & $-4 \%$ & $19 \%$ & $18 \%$ & $+1 \%$ & $14 \%$ & $15 \%$ & $-1 \%$ \\
\hline $8: 01-8: 30$ & $21 \%$ & $19 \%$ & $+3 \%$ & $18 \%$ & $17 \%$ & $-2 \%$ & $17 \%$ & $16 \%$ & $+2 \%$ \\
\hline $8: 31-9: 00$ & $18 \%$ & $7 \%$ & $+11 \%$ & $17 \%$ & $19 \%$ & $-2 \%$ & $19 \%$ & $17 \%$ & $+2 \%$ \\
\hline $9: 01-9: 30$ & $7 \%$ & $9 \%$ & $-2 \%$ & $7 \%$ & $7 \%$ & - & $10 \%$ & $9 \%$ & $+1 \%$ \\
\hline After 9:30 & $11 \%$ & $4 \%$ & $+7 \%$ & $13 \%$ & $10 \%$ & $+3 \%$ & $18 \%$ & $17 \%$ & $+1 \%$ \\
\hline \multicolumn{10}{|l|}{$\begin{array}{l}\text { Socio } \\
\text { Economic } \\
\text { Group }\end{array}$} \\
\hline $\begin{array}{l}\text { Employers and } \\
\text { managers }\end{array}$ & $16 \%$ & $12 \%$ & $+4 \%$ & $12 \%$ & $7 \%$ & $+5 \%$ & $10 \%$ & $7 \%$ & $+3 \%$ \\
\hline $\begin{array}{l}\text { Higher } \\
\text { professional }\end{array}$ & $17 \%$ & $5 \%$ & $+2 \%$ & $16 \%$ & $11 \%$ & $+5 \%$ & $15 \%$ & $8 \%$ & $+7 \%$ \\
\hline $\begin{array}{l}\text { Lower } \\
\text { professional }\end{array}$ & $20 \%$ & $16 \%$ & $+4 \%$ & $17 \%$ & $12 \%$ & $+5 \%$ & $18 \%$ & $11 \%$ & $+7 \%$ \\
\hline Non-manual & $22 \%$ & $22 \%$ & - & $24 \%$ & $21 \%$ & $+3 \%$ & $23 \%$ & $22 \%$ & $+1 \%$ \\
\hline Manual Skilled & $6 \%$ & $11 \%$ & $-5 \%$ & $9 \%$ & $16 \%$ & $-7 \%$ & $7 \%$ & $12 \%$ & $-5 \%$ \\
\hline Semi-skilled & $10 \%$ & $13 \%$ & $-3 \%$ & $14 \%$ & $18 \%$ & $-4 \%$ & $13 \%$ & $19 \%$ & $-6 \%$ \\
\hline Unskilled & $3 \%$ & $5 \%$ & $-2 \%$ & $3 \%$ & $7 \%$ & $-4 \%$ & $6 \%$ & $11 \%$ & $-5 \%$ \\
\hline $\begin{array}{l}\text { Own account } \\
\text { workers }\end{array}$ & $1 \%$ & $1 \%$ & - & $1 \%$ & $2 \%$ & $-1 \%$ & $2 \%$ & $1 \%$ & $+1 \%$ \\
\hline Farmers & $0 \%$ & $0 \%$ & - & $1 \%$ & $1 \%$ & - & $2 \%$ & $3 \%$ & $-1 \%$ \\
\hline $\begin{array}{l}\text { Agricuitural } \\
\text { workers }\end{array}$ & $0 \%$ & $0 \%$ & $=$ & $0 \%$ & $1 \%$ & $-1 \%$ & $0 \%$ & $1 \%$ & $-1 \%$ \\
\hline All other & $3 \%$ & $5 \%$ & $-2 \%$ & $2 \%$ & $4 \%$ & $-2 \%$ & $4 \%$ & $5 \%$ & $-1 \%$ \\
\hline \multicolumn{10}{|l|}{$\begin{array}{l}\text { Average travel } \\
\text { time }\end{array}$} \\
\hline $\begin{array}{l}\text { Less than } 5 \\
\text { mins }\end{array}$ & $4 \%$ & $4 \%$ & $=$ & $11 \%$ & $10 \%$ & $1 \%$ & $10 \%$ & $13 \%$ & $-3 \%$ \\
\hline $6-10$ mins & $14 \%$ & $16 \%$ & $-2 \%$ & $24 \%$ & $26 \%$ & $-2 \%$ & $26 \%$ & $28 \%$ & $-2 \%$ \\
\hline $11-15$ mins & $19 \%$ & $20 \%$ & $-1 \%$ & $20 \%$ & $21 \%$ & $-1 \%$ & $23 \%$ & $23 \%$ & - \\
\hline $16-20$ mins & $21 \%$ & $20 \%$ & $+1 \%$ & $19 \%$ & $18 \%$ & $+1 \%$ & $19 \%$ & $16 \%$ & $+3 \%$ \\
\hline $21-30$ mins & $25 \%$ & $23 \%$ & $+2 \%$ & $17 \%$ & $16 \%$ & $+1 \%$ & $17 \%$ & $14 \%$ & $+3 \%$ \\
\hline $\begin{array}{l}31 \text { mins or } \\
\text { more }\end{array}$ & $16 \%$ & $15 \%$ & $+1 \%$ & $9 \%$ & $7 \%$ & $+2 \%$ & $6 \%$ & $6 \%$ & $\cdot$ \\
\hline
\end{tabular}


Table 5

Click here to download high resolution image

Table 5 Model results

\begin{tabular}{|c|c|c|c|}
\hline & & $\begin{array}{l}\text { No Change in } \\
\text { Cycling }\end{array}$ & Increase in cycling \\
\hline Intercept & & $1.089^{*}$ & $0.918^{*}$ \\
\hline \multirow[t]{2}{*}{ Gender } & Female & $-0.09^{* 4}$ & $-0.071^{*}$ \\
\hline & Male & Ref. & Ref. \\
\hline \multirow[t]{6}{*}{ Age } & $15-24$ & $-0.541^{* *}$ & $-0.353^{* *}$ \\
\hline & $25-34$ & $-0.487^{* *}$ & $-0.334^{*}$ \\
\hline & $35-44$ & $-0.391^{* *}$ & $0.422^{* *}$ \\
\hline & $45-54$ & $-0.268^{* *}$ & $0.163^{*}$ \\
\hline & $55-64$ & $-0.283^{* *}$ & $-0.189^{* *}$ \\
\hline & $65+$ & $\mathrm{Ob}$ & $\mathrm{Ob}$ \\
\hline \multirow[t]{5}{*}{ Number of cars } & One & $0.155^{*}$ & $0.430^{* 0}$ \\
\hline & Two & $0.365^{*}$ & $-0.598^{* *}$ \\
\hline & Three & $0.477^{* *}$ & $-0.498^{* *}$ \\
\hline & Four or more & $0.504^{* *}$ & $-0.491^{* *}$ \\
\hline & None & Ref. & Ref. \\
\hline \multirow[t]{9}{*}{ Departure time } & Not stated & $0.123^{* *}$ & $0.008^{* *}$ \\
\hline & Before 06:30 & $0.104^{* *}$ & $-0.136^{* *}$ \\
\hline & $06: 30-07: 00$ & $0.040^{* *}$ & $=0.171^{*}$ \\
\hline & $07: 01-07: 30$ & $-0.008^{\circ}$ & $-0.101^{*}$ \\
\hline & $07: 31-08: 00$ & $0.025^{*}$ & $0.046^{* *}$ \\
\hline & $08: 01-08: 30$ & $0.031^{*}$ & $0.182^{* *}$ \\
\hline & $08: 31-09: 00$ & $0.048^{*}$ & $0.177^{* *}$ \\
\hline & $09: 01-09: 30$ & $0.046^{*}$ & $0.164^{\circ}$ \\
\hline & After 09:30 & Ref. & Ref. \\
\hline \multirow{7}{*}{ Travel time } & & & \\
\hline & Less than 5 mins & $-0.060^{\circ}$ & $-0.287^{\circ}$ \\
\hline & $6-10$ mins & $-0.151^{* *}$ & $-0.157^{* 0}$ \\
\hline & $11-15$ mins & $-0.220^{* *}$ & $0.028^{* *}$ \\
\hline & $16-20$ mins & $-0.215^{* *}$ & $0.166^{* *}$ \\
\hline & $21-30$ mins & $-0.135^{* *}$ & $0.22^{* *}$ \\
\hline & 31 mins or more & Ref. & Ref. \\
\hline \multirow[t]{11}{*}{$\begin{array}{l}\text { Socio-economic } \\
\text { group }\end{array}$} & $\begin{array}{l}\text { Employers and } \\
\text { managers }\end{array}$ & $0.356^{* *}$ & $0.582^{* *}$ \\
\hline & Higher professional & $0.506^{*}$ & $0.939^{* *}$ \\
\hline & Lower professional & $0.292^{* *}$ & $0.645^{* \hbar}$ \\
\hline & Non-manual & $0.049^{* *}$ & $0.139^{* *}$ \\
\hline & Manual skilled & $-0.272^{* *}$ & $-0.079^{* *}$ \\
\hline & Semi-skilled & $-0.188^{* *}$ & $-0.128^{* *}$ \\
\hline & Unskilled & $-0.287^{* *}$ & $=0.096^{\circ}$ \\
\hline & Own account workers & $0.083^{*}$ & $0.375^{\star *}$ \\
\hline & Farmers & $1.308^{*}$ & $0.055^{*}$ \\
\hline & Agricultural workers & $0.978^{*}$ & $0.044^{* *}$ \\
\hline & $\begin{array}{l}\text { All others gainfully } \\
\text { occupied and unknown }\end{array}$ & Ref. & Ref. \\
\hline \multicolumn{3}{|c|}{ 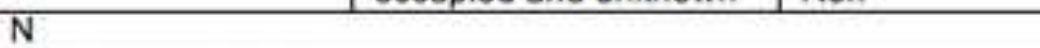 } & 467,070 \\
\hline \multicolumn{3}{|c|}{-2 log-likelihood at convergence } & 27166.338 \\
\hline \multicolumn{3}{|c|}{ Nage kerke R2 } & 0.110 \\
\hline \multicolumn{3}{|c|}{ Chi-squared statistic } & 47399.155 \\
\hline \multicolumn{3}{|c|}{ Degrees of freedom } & 86 \\
\hline
\end{tabular}

* Significant at $99 \%$ confidence level

- Significant at $95 \%$ confidence ievel 
Figure 1

Click here to download high resolution image

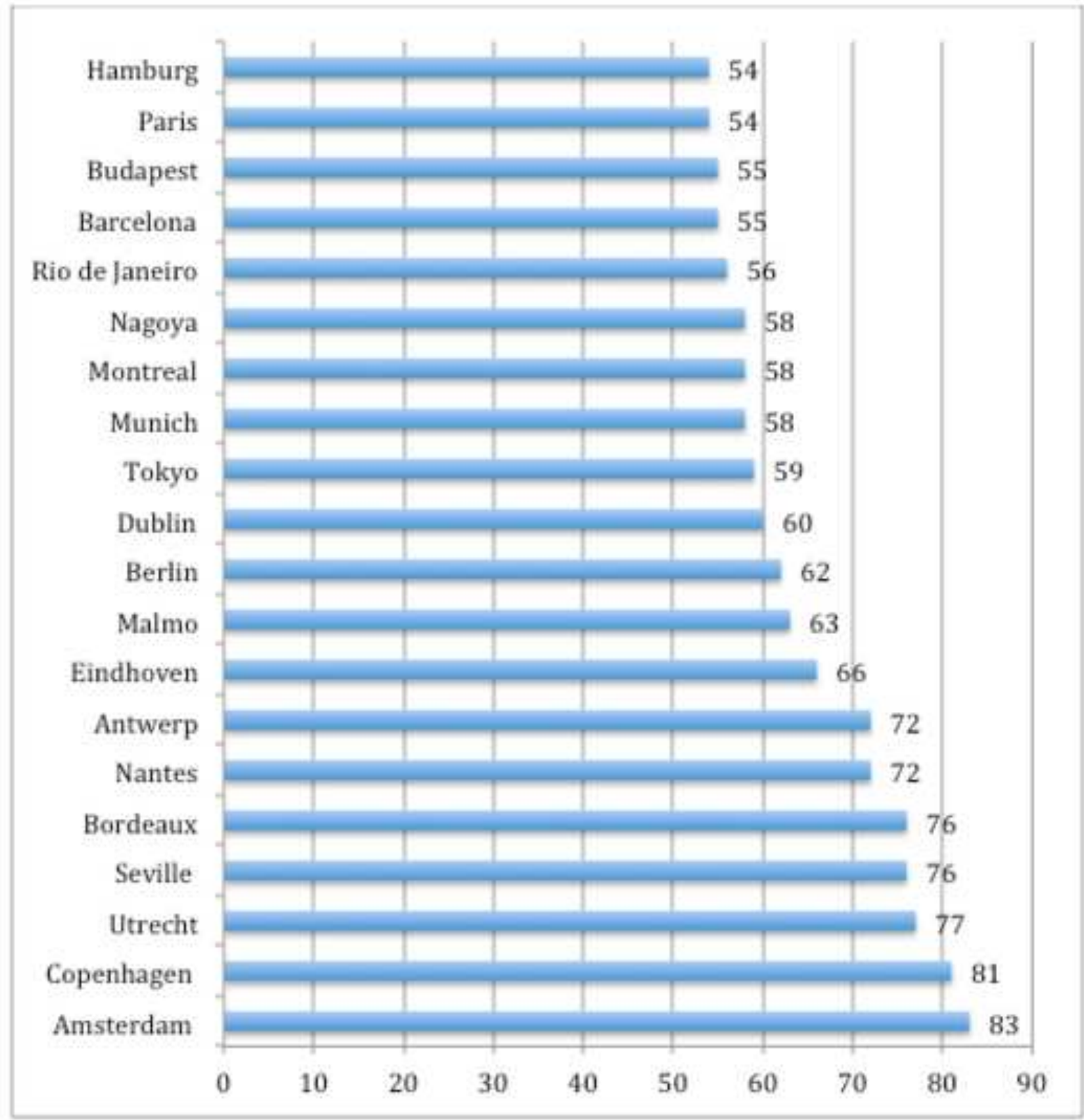

Figure 1 COPENHAGENIZE Index 2013 (COPENHAGENIZE, 2013) 

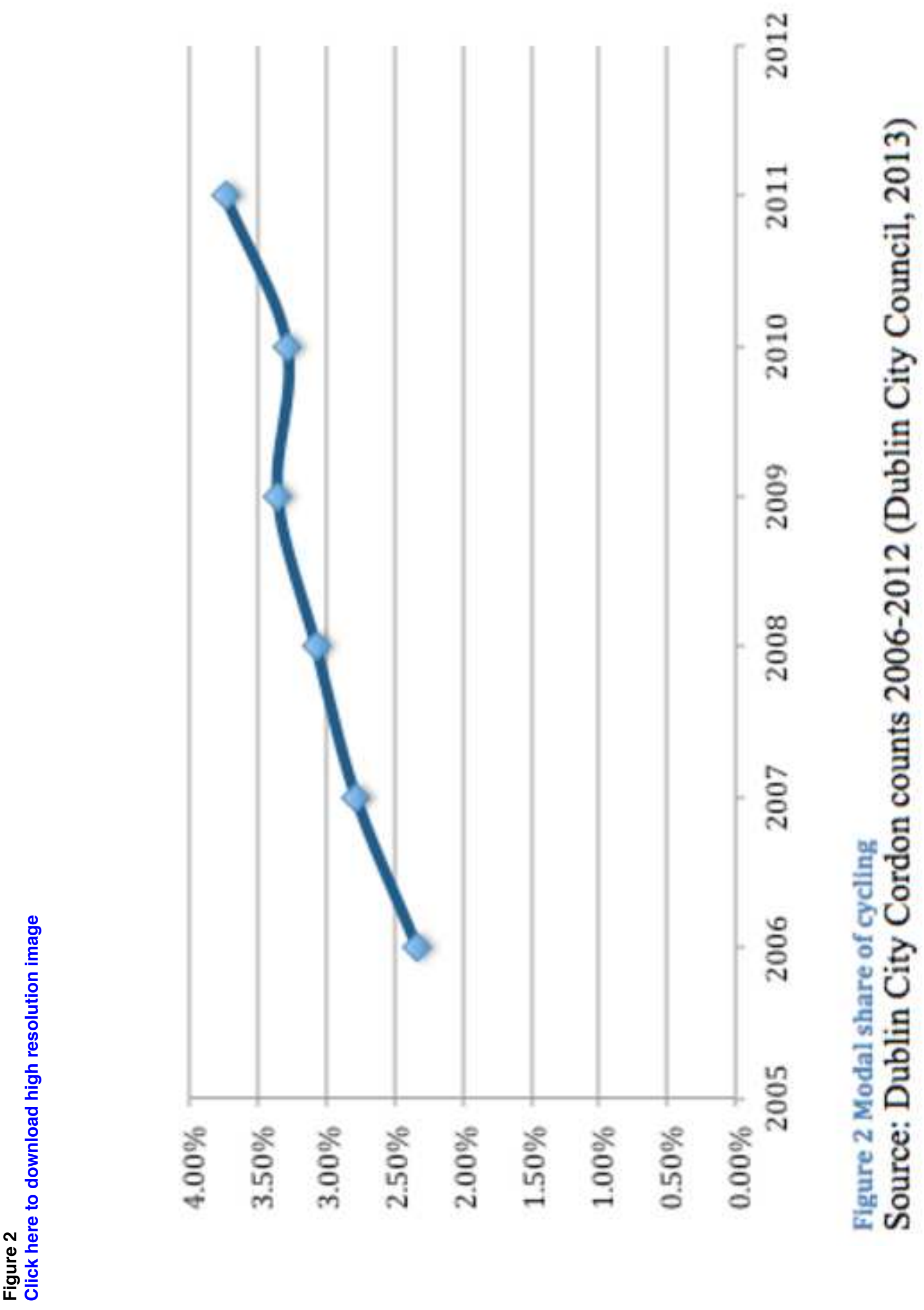
Figure 3

Click here to download high resolution image

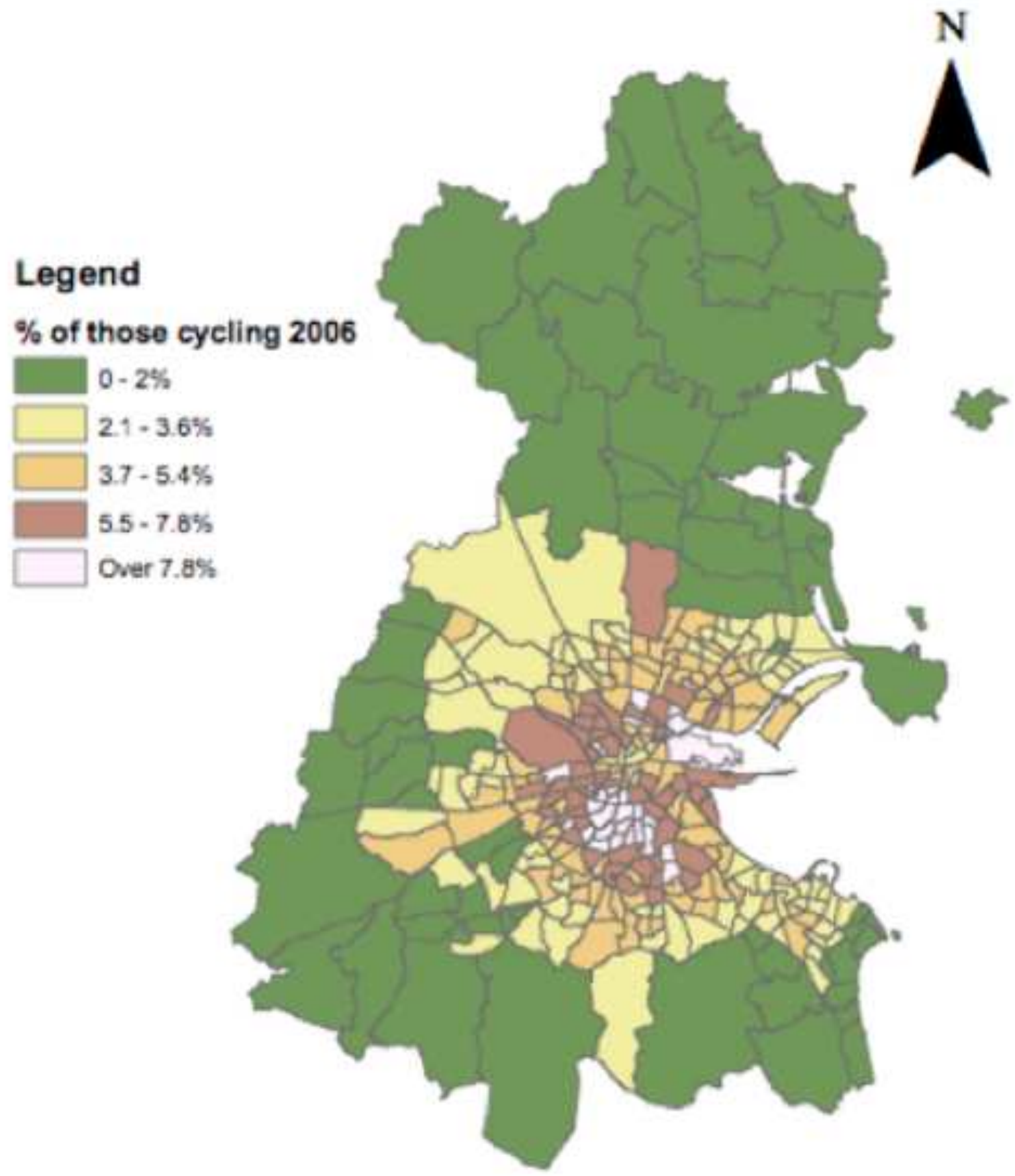

Figure 3: \% of those cycling to work 2006 
Figure 4

Click here to download high resolution image

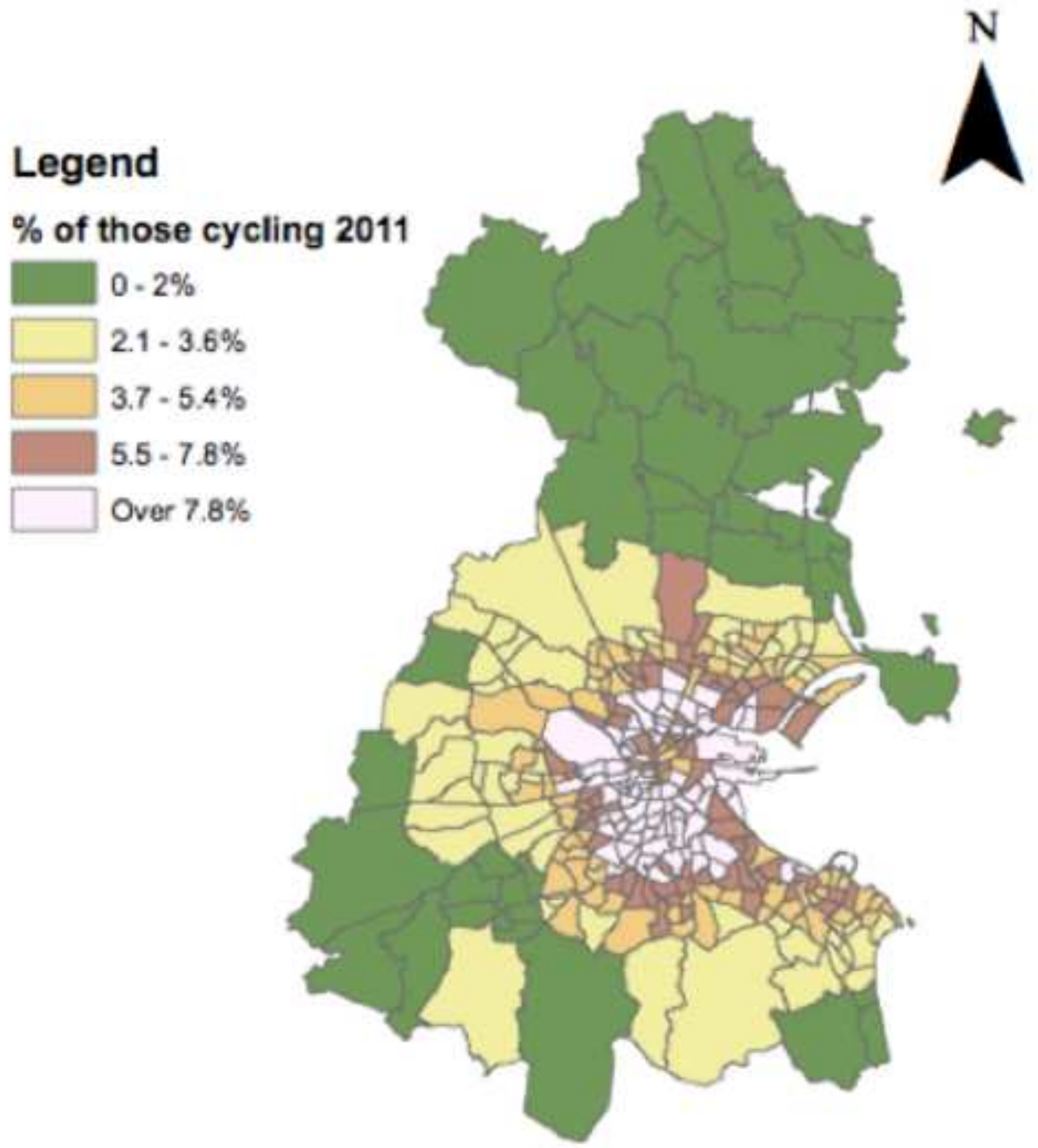

Figure 4: \% of those cycling to work 2011 


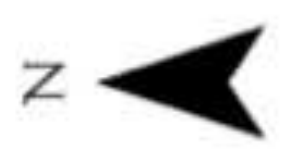

$\$$

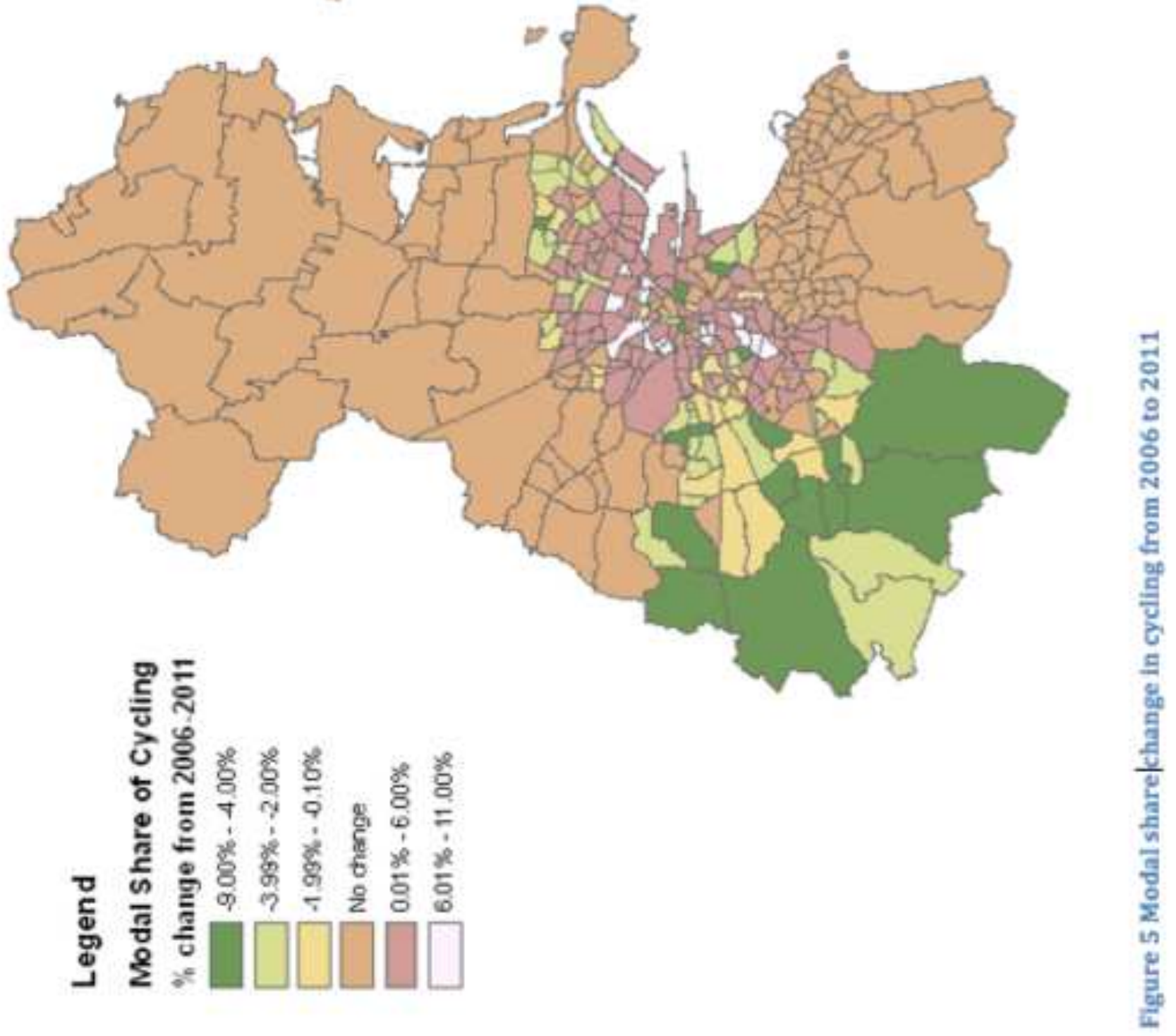

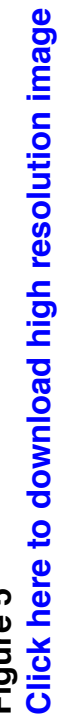

